\title{
Sciatic Nerve Injuries from Gluteal Intramuscular Injection According to Records of the High Health Council
}

\author{
Hakan Hadi KADIOGLU1,2 \\ ${ }^{1}$ Ataturk University, Department of Neurosurgery, Erzurum, Turkey \\ ${ }^{2} \mathrm{High}$ Health Council, Ankara, Turkey
}

\section{ABSTRACT}

AIM: To analyze the cases discussed at the High Health Council $(\mathrm{HHC})$ and to determine the solutions for problems related to gluteal intramuscular injection (IMI) applications.

MATERIAL and METHODS: In a 10-year period, the cases of IMI-related sciatic nerve injury (SNI) referred for an opinion from the $\mathrm{HHC}$ of Turkey were reviewed. The cases were analyzed based on demographic features, degree of nerve damage, side of gluteal injection, injected drugs, primary disease, appropriateness of parenteral therapy indications, and management.

RESULTS: There were 107 SNIs from gluteal IMI during the 103 months. Eight of the 107 cases were male and 99 female. The mean age was 28 years. The left sciatic nerve was more commonly injured (41 right, 65 left side). SNI was partial in $48.5 \%$ of the cases. The most commonly injected drug was diclofenac sodium (29.9\%), and $23.3 \%$ of cases were injected more than one drug together. Conservative management was performed in all cases, except one.

CONCLUSION: Based on our findings, indications of parenteral therapies were exaggerated and nurses injected the drug while the patient's position was inappropriate for IMI. However, an IMI into the gluteal region is potentially devastating. For those reasons, we conclude that physicians should be restricted in their indications for IMI, and continuous education courses should be organized for nurses. Injured patients should be managed according to their neurological damage.

KEYWORDS: Injury, Intramuscular injection, Sciatic nerve

\section{INTRODUCTION}

S ciatic nerve injury after an intramuscular (IM) injection into the buttock is potentially devastating (12). In severely damaged cases, it causes paralytic drop foot deformities of the extensor muscles of the ankle and toe. This avoidable complication, known since the beginning of the $20^{\text {th }}$ century, has been extensively reviewed in the literature of nursing practice $(10,12,16,18)$. latrogenic injury of the sciatic nerve is frequently seen, leading to temporary or permanent disability that can result in medicolegal claims $(14,18)$. However, the majority of physicians need to prescribe medication that can be prescribed with IM injection (e.g., analgesics, antiinflammatories, antibiotics, vitamins, steroid hormones, analgesics and major sedatives) and all health professionals should consider safe injection rules.

\section{MATERIAL and METHODS}

A retrospective review was conducted on the records of cases with sciatic nerve injuries related to gluteal intramuscular injection referred to the High Health Council ( $\mathrm{HHC}$ ) of Turkey by searching case records spanning approximately a 10-year period (2003-2013). Among cases discussed at the HHC, 107 cases, which form the basis of this study, concerning sciatic nerve lesions were identified. In these cases, the complaints were secondary to various unexpected outcomes 
of the medical application. One hundred and seven cases with sciatic injury related to gluteal intramuscular injection were analyzed based on demographic features, degree of nerve damage, side of gluteal region used, injected drugs, primary disease, appropriateness of parenteral therapy indications, and management.

\section{RESULTS}

This paper reports the cases of sciatic nerve injuries as a result of gluteal intramuscular injection based on the $\mathrm{HHC}$ records for about a period of 10 years. This study is based on the recordings, which are medical documents in judicial papers, received by the HHC. Unfortunately, there is no information regarding the injection area. There were 107 cases in the study period, 99 of them were female and 8 were males. The mean age was 28 years. The overall male to female ratio was 0.08 . The age range at injury was 3-79 years (mean 27.5 years); for men 3-79 years (mean 41 years), and for women 9-67 (mean 38 years). There is significant difference between men and women (Table I). The sides of injured nerve are shown in Table II. The left sciatic nerve was injured more frequently $(61 \%)$. Table III shows the degree of nerve damage related to injection. Results of clinical evaluation and electrophysiological examination of 80 patients showed that the sciatic nerve neuropathies due to injection were more common in the peroneal branch than in the tibial branch. In 51 patients, the peroneal branch was more severely involved and 24 were complete lesions; in 17 patients both branches were involved equally and 2 were complete lesions; in 12 patients, the tibial branch was more severely affected and 2 were complete lesions. It was observed that one branch of sciatic nerve damage was often injured, but this damage could be complete or partial. It was determined that 63 of the cases complained about instant onset radicular pain, paresthesia, and/or progressive motor deficit after the injection. Seventeen patients (15.9\%) complained of chronic progressive palsy that developed within hours or days after the injection. Therefore, in these cases, a delayed onset of pain, paresthesia, and/or motor deficit were observed ranging from hours to days (Table IV). The most common intramuscularly delivered agents were anti-inflammatory and analgesic agents, antipyretics, antibiotics, and antiemetics (Table V). The data in Table VI pointed out that the drugs injected in the buttocks were prescribed for non-specific symptoms such as myalgia, hyperpyrexia, abdominal pain, headache, etc.

\section{DISCUSSION}

The most common cause of iatrogenic injuries of the sciatic nerve is hip surgery and the second is the gluteal intramuscular injections (15). Injection injury is more likely to occur in individuals with a thin or poorly constructed buttock, such as constitutionally thin or chronically ill and debilitated individuals. Infants and young children as well as elderly individuals are also very frequently afflicted because of the higher nerve vulnerability $(3,17,21)$.

The patient's position is an important factor for an appropriate injection. The incidence may also be increased if a patient receives an injection in the buttock while he or she is in a lateral and recumbent position or is standing and bent over (11). The ventrogluteal region has been proposed for gluteal injections to decrease the sciatic injury risk. All the intramuscular injection sites are hazardous. The ventrogluteal region has been said to be safer than the dorsolateral area (13). However, this applies only with the patient lying in the prone or lateral position. When the patient is sitting, the normal anatomical landmarks become distorted and there is an increased chance of the needle impinging upon this vital structure. Because of this, intramuscular injections in the gluteal region should be performed with the patient lying rather than sitting (4). However, nurses are reluctant to use this area for intramuscular injections $(2,12,18,22)$. Indeed, in a recent survey in New

Table I: Demographic Features of the Cases

\begin{tabular}{|c|c|c|c|c|c|c|c|c|c|c|c|c|c|c|c|c|c|c|c|}
\hline \multirow{2}{*}{$\begin{array}{l}\text { Age } \\
\text { (years) }\end{array}$} & & \multicolumn{2}{|c|}{$<7 y$} & \multicolumn{2}{|c|}{ 8-15 } & \multicolumn{2}{|c|}{$16-20$} & \multicolumn{2}{|c|}{$21-30$} & \multicolumn{2}{|c|}{$31-40$} & \multicolumn{2}{|c|}{$41-50$} & \multicolumn{2}{|c|}{$51-60$} & \multicolumn{2}{|c|}{$>60$} & \multicolumn{2}{|c|}{ Total } \\
\hline & & $\mathrm{n}$ & $\%$ & $n$ & $\%$ & $n$ & $\%$ & $n$ & $\%$ & $n$ & $\%$ & $n$ & $\%$ & $n$ & $\%$ & $n$ & $\%$ & $\mathrm{n}$ & $\%$ \\
\hline \multirow{2}{*}{ Gender } & Male & 1 & 0.9 & 1 & 0.9 & 0 & 0 & 2 & 1.8 & 1 & 0.9 & 2 & 1.8 & 0 & 0 & 1 & 0.9 & 8 & 7.8 \\
\hline & Female & 0 & 0 & 9 & 8.4 & 17 & 15.8 & 28 & 26.1 & 7 & 6.5 & 21 & 19.6 & 8 & 7.4 & 9 & 8.4 & 99 & 92.2 \\
\hline Total & & 1 & 0.9 & 10 & 9.3 & 17 & 15.8 & 30 & 27.9 & 8 & 7.4 & 23 & 21.4 & 8 & 7.4 & 10 & 9.3 & 107 & 100.0 \\
\hline
\end{tabular}

Table II: Side Injured by Injection

\begin{tabular}{lcc}
\hline Side & $\mathbf{n}$ & \% \\
\hline Right & 41 & 38.3 \\
\hline Left & 65 & 60.8 \\
\hline Undetermined & 1 & 0.9 \\
\hline Total & $\mathbf{1 0 7}$ & $\mathbf{1 0 0 . 0}$ \\
\hline
\end{tabular}

Table III: Severity of Nerve Damage by Injection

\begin{tabular}{lcc}
\hline Damage & $\mathbf{n}$ & \% \\
\hline Partial damage & 52 & 48.5 \\
\hline Total damage & 28 & 26.2 \\
\hline Unknown & 27 & 25.3 \\
\hline Total & $\mathbf{1 0 7}$ & $\mathbf{1 0 0 . 0}$ \\
\hline
\end{tabular}


Table IV: Time Interval Between the Injection and the First Complaints

\begin{tabular}{lcc}
\hline Time & $\mathbf{n}$ & \% \\
\hline Instantly & 63 & 58.8 \\
\hline One day & 4 & 3.7 \\
\hline More than one day & 13 & 12.2 \\
\hline Unknown & 27 & 25.3 \\
\hline Total & $\mathbf{1 0 7}$ & $\mathbf{1 0 0 . 0}$ \\
\hline
\end{tabular}

Table V: The Injected Drugs

\begin{tabular}{|c|c|c|}
\hline Drugs & $\mathbf{n}$ & $\%$ \\
\hline Diclofenac (Dicloran ${ }^{\circledR}$ ) & 16 & 14.9 \\
\hline Diclofenac (Diclomec ${ }^{\circledR}$ ) & 7 & 6.5 \\
\hline Diclofenac $\left(\right.$ Voltaren $\left.{ }^{\circledR}\right)$ & 5 & 4.6 \\
\hline Diclofenac (Myadren ${ }^{\circledR}$ ) & 4 & 3.7 \\
\hline Fenyramidol $\left(\mathrm{Cabral}^{\circledR}\right)$ & 2 & 1.8 \\
\hline Metamizole (Novalgin ${ }^{\circledR}$ ) & 9 & 8.4 \\
\hline Metamizole (Adepiron ${ }^{\circledR}$ ) & 2 & 1.8 \\
\hline Thiocolchicoside $\left(\right.$ Muscoril ${ }^{\circledR}$ ) & 2 & 1.8 \\
\hline Diazepam $\left(\right.$ Diazem $\left.^{\circledR}\right)$ & 2 & 1.8 \\
\hline Ampicillin & 5 & 4.6 \\
\hline Gentamycin $\left(\right.$ Genta $\left.^{\circledR}\right)$ & 1 & 0.9 \\
\hline Clindamycin $\left(\right.$ Cleocin $\left.^{\circledR}\right)$ & 3 & 2.8 \\
\hline Hyoscine butylbromide (Buscopan ${ }^{\circledR}$ ) & 1 & 0.9 \\
\hline Dimenhydrinate $\left(\right.$ Dramamine $^{\circledR}$ ) & 2 & 1.8 \\
\hline Metoclopramide $\left(\right.$ Metpamid $^{\circledR}$ ) & 3 & 2.8 \\
\hline Ranitidine (Ulcuran ${ }^{\circledR}$ ) & 2 & 1.8 \\
\hline Multiple drug combination & 25 & 23.3 \\
\hline Undetermined & 9 & 8.4 \\
\hline Total & 107 & 100.0 \\
\hline
\end{tabular}

Zealand, only $9 \%$ of the nurses reported using this site for intramuscular injection $(6,12)$. This reluctance of the nurses may be partly due to the lack of confidence in identifying the area $(6,12,22)$. To avoid confusion between the dorsogluteal region and buttock definitions, it is even proposed to replace the term ventrogluteal with the term "gluteal triangle" (12). It is assumed that hand preferences of nurses are also factor in the sciatic injury sides. It is known that most people prefer the right hand. During gluteal injection, the nurse uses his/her right hand to inject the drug and the other hand for determining the injection site. Possibly, right-handed nurses confuse the
Table VI: Primary Disease that Required Intramuscular Injection Therapy

\begin{tabular}{lcc}
\hline Diseases & $\mathbf{n}$ & $\%$ \\
\hline Myalgia & 18 & 16.8 \\
\hline Colic renal/intestinal & 12 & 11.2 \\
\hline Acute abdomen & 6 & 5.6 \\
\hline Postoperative pain & 4 & 3.7 \\
\hline Extremities fractures & 5 & 4.6 \\
\hline Hemorrhoid & 4 & 3.7 \\
\hline Migraine & 3 & 2.8 \\
\hline Headache & 6 & 5.6 \\
\hline Upper respiratory tract infection & 5 & 4.6 \\
\hline Dental infection & 15 & 14 \\
\hline Hyperpyrexia & 5 & 4.6 \\
\hline Vertigo & 4 & 3.7 \\
\hline Cancer & 1 & 0.9 \\
\hline Hypertension & 7 & 6.5 \\
\hline Pulmonary infection & 3 & 2.8 \\
\hline Discopathy & 3 & 2.8 \\
\hline Trauma & 4 & 3.7 \\
\hline Undetermined & 1.8 \\
\hline Total & 3 & 100.0 \\
\hline
\end{tabular}

methods at the left side buttock and left-handed ones confuse them at the right side and therefore the injection coincides with the sciatic nerve when they are not using their preferred hand on the area that they are used to.

Unfortunately, there are not enough data in the analyzed records to support this assumption. Although there is no study on the group of health care professionals, it is known that 91$96 \%$ of the general population is right-handed $(5,23)$. In the study, the left gluteal area was used for injection in $61 \%$ of the cases. This data makes us think that determining the injection area by using the hand and fingers applied by a right-handed person on the left buttock as if it is applied on the right buttock may lead to confusion causing the sciatic nerve injury.

The fact that some chemical compounds are more destructive than others when injected into the peripheral nerves indicates that the chemical properties of intramuscular injected drugs are also important in nerve damage. The Wallerian degeneration resulting from the chemical damage caused by the drug injected into the peripheral nerve is distal after the first few weeks $(7,20)$. Some drugs were frequently encountered in the injured cases as they are more frequently prescribed by doctors. The injected material was only anti-inflammatory and analgesic drugs in $43.5 \%$ and only antibiotics in $8.3 \%$ of the 
patients. Multiple drug use was present in $23.3 \%$ of the cases and the agent that was used was not detected in $8.4 \%$.

When the drug is injected into the nerve, it causes pain, paresthesia, and/or motor deficit in the patient immediately after the injection $(7,20)$. A less common form that occurs in about $15 \%$ of cases is a delayed onset in terms of pain, dysesthesia, and/or motor deficit, ranging from minutes to hours. The difference in the appearance of neurodeficits may be due to the drug being injected into the epineurium of the peripheral nerve or close to the nerve.

In this study, there were 80 patients who were able to provide a history, and $63(58.8 \%)$ of them complained about sudden weakness alone or accompanying pain immediately after the injection. Seventeen (15.9\%) of the patients complained of chronic paralysis that progressed within hours or days. Clinical examination and electrophysiological findings from the 80 patients revealed that injection-related sciatic nerve injury was more frequent and severe in the peroneal branch compared to the tibial division. The peroneal branch was more seriously damaged in 56 patients; 21 of these had complex lesions; In 14 patients, both branches were equally distributed, one of them was a complete lesion while in 10 patients the tibial branch was more severely affected and one was a complete lesion. Neurological findings caused by intraneural injection are specific. In the typical history of the cases, it was found that with the placement of the injector needle, there is a sense of electrical shock which spreads along the leg. The most common clinical manifestation following injection of the drug included severe radicular leg pain and sensory disturbances and almost sudden onset variable motor and sensorial neurodeficits $(15,20)$.

Currently, evaluation of sciatic nerve injuries is performed by clinical examination, nerve conduction studies (NCS) and electromyography (EMG). NCS and EMG can define axonal damage in the nerve, but may not be able to determine the exact location of the lesion.

Furthermore, follow-up trials that cannot be performed due to the slow regeneration, incomplete and distal target should often be reached to regain an evoked muscle action potential at NCS or voluntary activity in the EMG. Magnetic resonance neurography (MRN) is a new technique that detects peripheral nerve injuries and visualizes nerve damage even at the fascicular microstructural level $(1,8,14,19)$. According to the literature, spontaneous healing is seen in the majority of the cases with injection injuries (21). Surgical exploration is recommended in patients whose spontaneous resolution is not determined clinically and electrophysiologically within the first two weeks after the initiation of injection-induced paralysis $(9,15)$. Topuz et al. reported that in cases where clinical evidence of a nerve transection is present, the nerve may be explored without waiting for electrophysiological confirmation. The late diagnosis and consequently the late treatment are attributed to the negative consequences in many cases so that they lead to accusations in judicial cases (20). Another issue in the treatment of these patients is the relief of pain. The possible solutions to alleviate the pain, depending on the situation, are waiting for a while, conservative treatment or surgery $(15,21)$.
When injection-required medical conditions were investigated, it was observed that acute pain was present in most of the cases. In other words, the most frequent reason for injection was to relieve and eliminate the pain of the patients. However, even if the other side effects are ignored, the injection itself causes acute pain. In our society, the tendency of patients and the relatives towards parenteral treatment directs doctors in their medical practices. For reduction of complications due to intramuscular injections, choosing the correct intramuscular treatment indications, and ensuring the appropriate conditions, technique and experience would be helpful.

\section{CONCLUSION}

There is no site without hazard for intramuscular injection. When the buttock was chosen, it should be kept in mind that the ventrogluteal region is safer than the dorsolateral area. The study was conducted using documents received by the HCC from the courts. It is supposed that the actual number of the sciatic nerve injury cases is more than that presented to the court.

In this study, it was seen that there is usually no indication for treatment with intramuscular injection. However, drugs given by intramuscular injection are still prescribed frequently in Turkey.

Sciatic nerve lesions due to gluteal injections are not rare even if the health care personnel has been trained properly. Safe injection training should therefore be periodically organized for all health care professionals.

The medication and the site of injection should be chosen with great care. At the same time, the patient's buttock mass should be considered, especially in the elderly and children that have thin or poorly constructed buttocks.

\section{ACKNOWLEDGMENT}

This study was prepared for publication on permission given by resolution 2016/13770 of the High Health Council of Turkey.

\section{- REFERENCES}

1. Bendszus M, Stoll G: Technology insight: Visualizing peripheral nerve injury using MRI. Nat Clin Pract Neurol 1:45-53, 2005

2. Carter-Templeton $\mathrm{H}, \mathrm{McCoy} \mathrm{T}$ : Are we on the same page? A comparison of intramuscular injection explanations in nursing fundamental texts. Medsurg Nursing 17: 237-240, 2008

3. Clark K, Williams PE Jr, Willis W, McGavran WL 3rd: Injection injury of sciatic nerve. Clin Neurosurg 17:111-125, 1970

4. DePrizio CJ: Liability and the buttocks. N Engl J Med 280: 1186, 1969

5. Elalmis DD, Tan U: Hand preference in Turkish population. Int J Neurosci 115:705-712, 2005

6. Floyd S, Meyer A: Intramuscular injections - what's best practice? Why is there such a gap between what is taught in nursing schools about the best sites end technique for intramuscular injections and what actually happens in practice? Two nurses decided to find out. N Z Nurs J 13: 2022,2007 
7. Gentili F, Hudson AR, Midha R: Peripheral nerve injuries: Types, causes, and grading. In: Wilkins $\mathrm{RH}$, Rengachary SS (eds). Neurosurgery. Vol: 3. New York: McGraw-Hill, 1997: 3105-3114

8. Grant GA, Britz GW, Goodkin R, Jarvik JG, Maravilla K, Kliot $M$ : The utility of magnetic resonance imaging in evaluating peripheral nerve disorders. Muscle Nerve 25: 314-331, 2002

9. Kim DH, Murovic JA, Tiel R, Kline DG: Management and outcomes in 353 surgically treated sciatic nerve lesions. J Neurosurg 101: 8-17, 2004

10. Malkin B: Are techniques used for intramuscular injection based on research evidence? Nurs Times 104: 48-51, 2008

11. Midha R: Peripheral nerve: Approach to the patient. In: Winn HR (ed). Youmans Neurological Surgery. $5^{\text {th }}$ ed. Philadelphia: Saunders, 2004: 3819-3830

12. Mishra P, Stringer MD: Sciatic nerve injury from intramuscular injection: A persistent and global problem. Int J Clin Pract 64: 1573-1579, 2010

13. Muller-Vahl $\mathrm{H}$ : Isolated complete paralysis of the tensor fasciae latae muscle. Eur Neurol 24: 289-291, 1985

14. Pham M, Wessig C, Brinkoff J, Reiners K, Stoll G, Bendzus M: MR neurography of sciatic nerve injection. J Neurol 258: 1120-1125, 2011
15. Plewnia C, Wallace C, Zochodne D: Traumatic sciatic neuropathy: A novel cause, local experience, and a review of the literature. J Trauma 47:986-991, 1999

16. Rodger MA, King L: Drawing up and administering intramuscular injections: A review of the literature. J Adv Nurs 31: $574-582,2000$

17. Senes FM, Campus MD, Becchetti F, Catena N: Sciatic nerve injection palsy in the child: Early microsurgical treatment and long-term results. Microsurgery 29: 443-448, 2009

18. Small SP: Preventing sciatic nerve injury from intramuscular injections: Literature review. J Adv Nurs 47: 287-296, 2004

19. Stoll G, Bendzus M, Perez J: Magnetic resonance imaging of the peripheral nervous system. J Neurol 256:1043-1051, 2009

20. Topuz K, Kutlay M, Simsek H, Atabey C, Demircan M, Guney MS: Early surgical treatment protocol for sciatic nerve injury due to injection-retrospective study. Br J Neurosurg 25: 509515,2011

21. Villarejo FJ, Pascual AM: Injection injury of the sciatic nerve (370 cases). Childs Nerv Syst 9: 229-232, 1993

22. Wynaden D, Landsborough I, McGowan S, Baigmohamad Z, Finn M, Pennebaker D: Best practice guidelines for the administration of intramuscular injections in the mental health setting. Int J Mental Health Nurs 15:195-200, 2006

23. Yildirim S, Dane S: Serebral lateralizasyon ve el tercihi. (Cerebral lateralization and hand preference). EAJEM 39: 4548, 2007 (In Turkish) 